\title{
A pigeon magazine shutter for preventing unprogrammed grain reinforcement'
}

W. R. LECKRONE AND J. ZIMMERMAN, INDIANA UNIVERSITY SCHOOL OF MEDICINE

P. V. HANFORD, INDIANA UNIVERSITY, INDIANAPOLIS CAMPUS

A modification of the standard pigeon magazine is described. A transparent shutter, which can be displaced by the action of a solenoid and silent clutch, covers the aperture through which access to grain can be provided. This device permits the presentation of all the visual and auditory stimuli which accompany food presentation while preventing access to food at all times except when food reinforcement is programmed.

Operant studies of conditioned reinforcement with pigeons employ a standard experimental space (Ferster \& Skinner, 1957). When conditioned reinforcement consists of the brief presentation of all the stimuli which accompany grain reinforcement and includes raising the magazine, the problem of preventing unprogrammed or accidental grain reinforcement can be especially critical. In research currently underway in this laboratory, we employ the brief presentation of the magazine cycle as a response-contingent conditioned reinforcement. Pecking behavior is maintained indefinitely under conditions in which grain reinforcement is concurrently and independently available (Zimmerman, 1963). Behaviors sustained on the basis of conditioned reinforcement under these conditions can be utilized as baselines against which to assess the effects of variables related to the maintenance of behavior by conditioned reinforcement (i.e., Zimmerman \& Hanford, 1966). Obviously, apparatus failures or malfunctioning which allow accidental access to food (i.e., "grain popping" or "hopper sticking") during a conditioned reinforcement cycle cannot be tolerated.

To prevent the occurrence of accidental feeding during the conditioned reinforcement cycle, we modified our Gerbrands'-type magazine as shown in Fig. 1. A 3-1/4in. by $5 / 8$-in. transparent, lucite shutter (D) covers the $1 / 2$-in. magazine aperture through which access to grain is provided. The shutter is moved aside only when the shutter-solenoid (A) is energized and a silent electromagnetic clutch (B) is engaged. The linear action of the shutter-solenoid plunger (G) is translated into the rotary motion of the clutch shaft by means of a clutch arm (I) which is attached to the solenoid plunger by pin (F) and piroted on the clutch shaft. The solenoid plunger is kept in a fixed extended position except when operated, by means of a spring $(\mathrm{H})$, and a stop $(\mathrm{J})$. The shutter is kept in place by a spring (E). When both the shutter-solenoid and clutch are energized, the shutter swings away from the aperture.

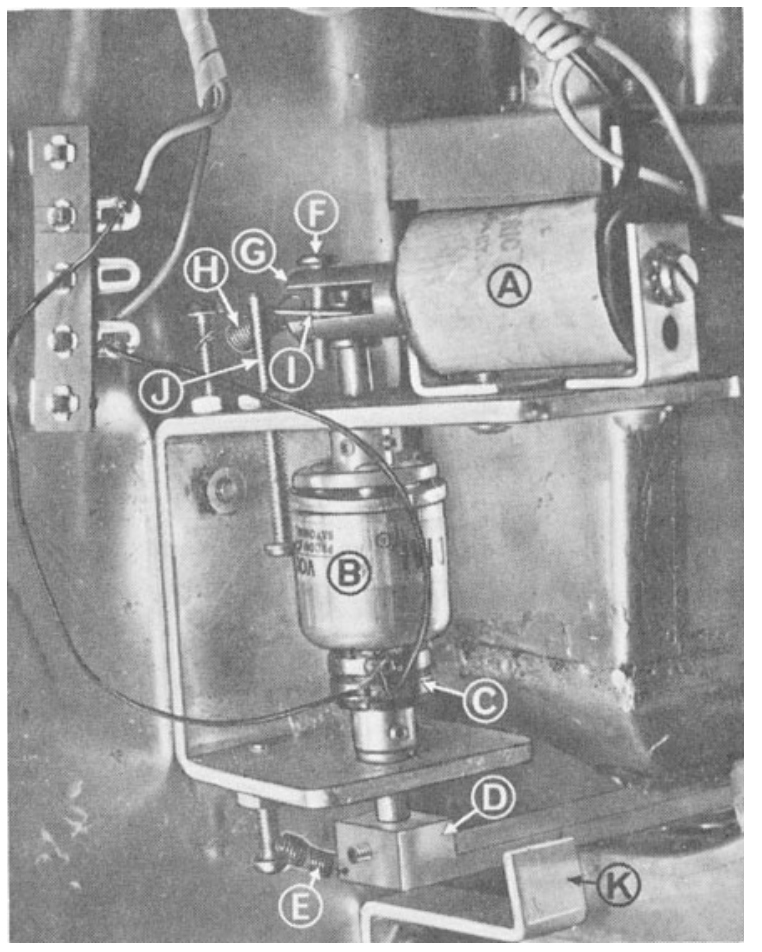

Fig. 1. Photograph of the modified portion of the pigeon magazine. A-shutter-solenoid (Guardian 1A1 AC 300 intermittent duty $115 V, 60$ cycle AC); B-silent, electromagnetic clutch (Dial CA 100, with a P-3 pole shoe, $28 \mathrm{~V}$ DC); $\mathrm{C}$-contacts for energizing clutch; D-lucite shutter; E-return spring for shutter; F-pin attaching shutter-solenoid plunger to clutch arm; G-shutter-solenoid plunger; H-return spring for plunger; I-clutch arm; J-stop for plunger; K-stop for shutter.

The shutter normally covers the magazine aperture and is displaced allowing access to food only when food reinforcement is programmed. Food is made available by simultaneously (a) energizing the hopper-solenoid (not shown) which raises the food hopper, (b) energizing the shutter-solenoid which turns the clutch shaft, and (c) engaging the silent clutch. Conditioned reinforcement is programmed by simultaneously energizing the hopper-solenoid and the shutter-solenoid but without engaging the clutch.Differential auditory cues associated with the two cycles (other than duration of stimulation) are eliminated by (a) the use of the silent clutch and (b) the use of a rubber stop which prevents the hopper from swinging up tightly under the access opening. During both cycles the distance between the grain and the opening is $6 \mathrm{~mm}$. This arrangement prevents the hopper from making contact with the shutter during a con- 
ditioned reinforcement cycle but still provides ready access to food during a food cycle. As a consequence, the stimuli presented during the conditioned reinforcement cycle are the same as those presented during the food cycle except for their brevity (1/2-sec. presentation) and the fact that only visual access to food is provided.

We are presently employing eight of these devices. Their introduction (approximately 16 months ago) did not markedly alter the behavior of any of the $15 \mathrm{Ss}$ (participating in one of four separate experiments) which had been previously reinforced with the old magazines. Four of the devices have been in daily use for well over one year and four others have been in daily use for at least four to eight months. When an occasional breakdown has occurred, it has involved the failure of the shutter-solenoid due to wear and this has merely resulted in the shutter remaining in its closed position during a food cycle.
The utilization of this device need not be confined to our particular application. Any study whose completion would be considerably postponed or whose results might be markedly or permanently altered by magazine failures which permit "grain stealing" or unprogrammed feeding would benefit from the implementation of this or a similar device.

\section{References}

Ferster, C. B., \& Skinner, B. F. Schedules of reinforcement. New York: Appleton-Century, 1957.

Zimmerman, J. Technique for sustaining behavior with conditioned reinforcement. Science, 1963, 142, 682-684.

Zimmenan, J., \& Hanford, P. V. Sustaining behavior with conditioned reinforcement as the only response-produced consequence. Psychol. Rep., 1966, 19, 391-401, in press.

\section{Note}

1. Development and utilization of this device has been supported, in part, by Grant No. MH 10741 from the National Institutes of Health, USPHS. 